Brazilian Journal

of Chemical

ISSN 0104-6632

Engineering

Printed in Brazil

www.scielo.br/bjce

Vol. 34, No. 04, pp. 949 - 959, October - December, 2017

$($ (c) $)$ EY

dx.doi.org/10.1590/0104-6632.2017034420160162

\title{
YEAST FERMENTATION OF SUGARCANE FOR ETHANOL PRODUCTION: CAN IT BE MONITORED BY USING IN SITU MICROSCOPY?
}

\author{
V. L. Belini' ${ }^{1}$ G. A. P. Caurin' ${ }^{2}$, P. Wiedemann ${ }^{3}$ and H. Suhr ${ }^{4}$ \\ ${ }^{1}$ Department of Electrical Engineering, Federal University of São Carlos, \\ Rodovia Washington Luís, km 235, São Carlos - SP, CEP 13565-905, Brazil \\ *E-mail: belini@ufscar.br; Phone: +55 (16) 3306-6618; Fax: +55 (16) 3351-9701. \\ ${ }^{2}$ Department of Mechanical Engineering, University of São Paulo, \\ Av. Trabalhador São-carlense, 400, São Carlos - SP, Brazil, CEP 13566-590 \\ ${ }^{3}$ Fakultät für Biotechnologie, Hochschule Mannheim, Paul-Wittsack-Straße 10, 68163, Mannheim, Germany \\ ${ }^{4}$ Fakultät für Informationstechnik, Hochschule Mannheim, Paul-Wittsack-Straße 10, 68163 Mannheim, Germany
}

(Submitted: March 10, 2016; Revised: October 30, 2016; Accepted: November 2, 2016)

\begin{abstract}
This paper addresses some key issues related to the automation of fermentation process analysis in the context of industrial-scale ethanol production from sugarcane substrates. As the current methods for the determination of cell density and viability are time consuming and laborious, high resolution in situ microscopy $(0.5 \mu \mathrm{m})$ is proposed as a promising alternative. Laboratory-scale experiments presented here show that this imaging technique allows automatic, on-line, and real-time monitoring of yeast cells suspended in sugarcane molasses used in the ethanol industry. In particular, the feasibility of cell concentration measurements of Saccharomyces cerevisiae SA-1 in industrial sugarcane molasses is demonstrated. Automated concentration measurements exhibit a linear correlation with manual reference values using a Neubauer chamber from $3 \times 10^{6}$ cells $/ \mathrm{mL}$ up to a saturation level at approximately $2 \times 10^{8}$ cells $/ \mathrm{mL}$. Furthermore, it was demonstrated that the microscopic resolution of this technique, combined with its large statistics, allows a morphological assessment of the size, shape and some internal structures of the yeast cells. On average, the accuracy of the algorithm's yeast cells classification was 0.80 . The results obtained suggest that the ISM is a suitable tool to perform in-line sugarcane fermentation monitoring.
\end{abstract}

Keywords: yeast, in situ microscopy, image analysis, sugarcane, molasses, ethanol.

\section{INTRODUCTION}

Traditionally, monitoring of physiological and morphological parameters of target microorganisms in industrial ethanol fermentations of sugarcane substrates has been performed using off-line processes, including sample extraction and preparation for subsequent manual analysis with a Neubauer counting chamber (hemocytometer) or electronic equipment.
Commercially available equipment, Countess (Thermo Fisher), Cedex (Roche), and Vicell (Beckman Coulter), for instance, are fast solutions that have automated the off-line image-based analysis of bioprocess parameters from manually prepared samples. However, they may have difficulties obtaining accurate measurements of suspensions that contain a diversity of cell-configurations, e.g. budding cells and cell agglomerations, which need to be distinguished. In manual counting, representative

\footnotetext{
* To whom correspondence should be addressed
} 
statistics from non-correlated samples in practical times are only possible by extraction, preparation and processing of many samples. Moreover, methylene blue staining, typically used in both manual and automated methods for viability studies, is notoriously inaccurate when the yeast viability is below 95\% (Wei and Sommer, 2010).

As an alternative, some state variables of the process, including optical density, $\mathrm{CO}_{2}$ or ethanol production rates, which can be measured on-line, can be used as indicators of the cellular biomass concentration and metabolic activities (Tibayrenc et al., 2010). However, no morphological information regarding the microbial populations can be inferred from these measurements. Moreover, their estimate accuracy relies on the assumption that only a pure culture, i.e., ideally suspended single cells in optically well-defined media, is under analysis. As consequence, they lack the capability of detecting the target microorganism and distinguishing between different microbial populations, as exist in practical fermenters. Techniques such as optical density become inaccurate if they are applied to complex fermentation media (Lynd et al., 2002).

This is a problem in plants producing ethanol from cane substrates, since they typically operate in non-aseptic conditions (Basso et al., 2011). Therefore, microbial contaminants are continuously introduced into the process, resulting in a dynamic competition between fermentative yeasts and bacteria and wild yeasts (Amorim et al., 2011), which may exhibit a variety of cell morphologies (Reis et al., 2013). Contaminations often affect the productivity of ethanolic fermentation, as they result in cell viability reduction (Oliva-Neto and Yokoya, 1994), the appearance of yeast-bacteria aggregation (Carvalho-Netto et al., 2015), yeast flocculation, excessive foam production, low fermentation yield, and incomplete sugar fermentation (Basso et al., 2008).

Moreover, filamentous growth in fermentative yeasts, as triggered by isoamyl alcohol (one of the major constituents of a variety of other alcohols produced by Saccharomyces cerevisiae), can also be troublesome to sugar fermentation processes, causing foam production, sugar cane juice flowing out the tanks, with sugar and alcohol loss (CeccatoAntonini, 2008). A recent study showed that a wild $S$. cerevisiae strain exhibiting pseudohyphal morphology is frequently associated with lower ethanol production and higher residual sugar content (Reis et al., 2013).

Without automated equipment at hand, the aforementioned manual counting chambers (e.g., Neubauer) can be used. Its application is inexpensive and well understood, but it provides estimates of yeast cell concentrations based on low statistical significance due to a limited amount of samples. Furthermore, deviations caused by the extraction of samples and subsequent sample processing steps make it difficult for any ex situ measurement to attain good reproducibility among different personnel and laboratories, particularly when using manual counting chambers. A general drawback of ex situ techniques is the effort needed to produce a continuous flow of data by extraction and processing of enough samples.

Taking all these observations together, it seems obvious that an automated in situ technique to determine cell density, cell viability and morphological information of the suspensions would be much preferable. Yet, despite many innovations, sugarcane fermentation processes for ethanol production still lack a suitable technology for the measurement of these parameters that could be integrated into the process supervisory and control system.

Therefore, this work proposes the application of in situ microscopy, including a suitable on-line image evaluation. An in situ microscope (ISM) offers detailed morphological information extracted from in situ images captured at a high frequency; thereby large amounts of uncorrelated visual data result in a small statistical uncertainty. Any uncertainty originating from sampling and sample preparation is also avoided.

The in situ microscopy concept was first described in 1991 by Suhr et al. Essentially, it consists of a transmitted light microscope that is directly coupled to moving suspensions of cells and particles so as to capture micrographs of the suspended cells and particles.

Only a few experimental studies on counting of yeast cells using an ISM have been published. The concentrations of yeasts detected were in the range of $10^{6}-10^{9}$ cells $/ \mathrm{mL}$ (Bittner et al., 1998; Suhr et al., 1995; Frerichs et al., 2001; Brückerhoff et al., 2005; Camisard et al., 2002; Wei et al., 2007). However, all of these studies relied on batch cultivations in chemically defined media, so that the application of in situ microscopy was facilitated by a homogeneous background and the absence of objects other than yeast cells.

Indeed, also previous work on image analysis applied to laboratory yeast samples is based on a homogeneous image background (Costello and Monk, 1985; Huls et al., 1992; Pons et al., 1993; Thomas and Paul, 1996; Tibayrenc et al., 2011). This precondition facilitates the application of standard image-processing operations as for example a threshold operation.

However, in the particular case of sugarcane fermentation, additional challenges for analyzing the yeast by imaging techniques in naturally dark brown, viscous molasses arise from the presence of the following micro-objects: yeast cell debris, endogenous microbial contaminants, solid, fibrous cane bagasse residues, small sugar crystals, and other non-cellular particles of varying sizes and amounts. This additional problem has to be overcome in image analysis used for the monitoring of sugarcane fermentation, regardless if the technique is online or off-line.

In this study, the necessary differentiation between yeast cells and other objects in ISM images is obtained by 
classifying detected objects on the basis of suitable feature values. Measures of size, roundness and inhomogeneity (granularity) were used in order to detect and to count the yeast cells in the sugarcane molasses. The ISM cell count is used as a measure for the cell concentration in the broth, which is one of the most important single parameters for fermentation control. In addition, it is demonstrated, that in situ microscopic information at the sub-micrometer level is obtained, which can be used to detect contaminating species as for example wild yeasts (de Souza Liberal et al., 2005; Reis et al., 2013). At large, in situ microscopy is demonstrated here to match the requirements of an in situ and real-time monitoring technique for sugarcane fermentation.

\section{MATERIALS AND METHODS}

\section{Microorganism, culture medium and growth conditions}

A commercial strain of Saccharomyces cerevisiae (SA-1), currently used for industrial ethanol production from sugarcane, was used in this study.

Lyophilized yeast cells $(2.9 \mathrm{~g})$ were re-hydrated with $20 \mathrm{~mL}$ of distilled water at $36^{\circ} \mathrm{C}, 70 \mathrm{rpm}$ for $15 \mathrm{~min}$.

Before in situ observations, the yeast was propagated in YPD ( $2 \%$ glucose, $2 \%$ peptone, and $1 \%$ yeast extract). Approximately $10 \mathrm{~g}$ (wet weight) of rehydrated yeast cells were inoculated into two 250-mL Erlenmeyer flasks containing $150 \mathrm{~mL}$ of YPD each. The flasks were incubated on a shaker at $32{ }^{\circ} \mathrm{C}, 120 \mathrm{rpm}$ for $74 \mathrm{~h}$. Subsequently, $4.7 \mathrm{~g}$ wet weight of the propagated cells recovered by centrifugation $(5000 \times g, 15 \mathrm{~min})$ was inoculated into 150 $\mathrm{mL}$ of $7^{\circ} \mathrm{Bx}$ cane molasses for the in situ experiments. The initial $\mathrm{pH}$ of the medium was adjusted to 4.5 .

Cane molasses is a dark brown, syrupy and sugar-rich liquid by-product of the sugar extraction process. The yeast and the molasses for the experiments were kindly provided by Santa Adélia S/A ethanol industry, Jaboticabal-SP, Brazil.

The highly concentrated substrate $\left(75^{\circ} \mathrm{Bx}\right)$ was diluted with distilled water to prepare a working molasses solution with a final concentration of $7^{\circ} \mathrm{Bx}$. This concentration differs from that used for feeding an industrial plant fermenter, where typical values are around $15-22{ }^{\circ} \mathrm{Bx}$ (Basso et al., 2011), but it is similar to values found in ethanol producing plants during the fermentation process.

To evaluate the ISM performance at different yeast cell concentrations, this study used a serial dilution procedure extended over $4 \mathrm{~h}$. It started with a high-density suspension of $3.3 \times 10^{8}$ cells $/ \mathrm{mL}$ (Neubauer) dispersed in the diluted molasses $\left(7^{\circ} \mathrm{Bx}\right)$. From this initial suspension, subsequent dilutions (1:3, 2:3, 1:2, 1:3, 1:5, and 1:2) were carried out using the same cell-free $7^{\circ} \mathrm{Bx}$ molasses as dilution medium.
This procedure represented a challenging task for the image evaluation by the ISM, because it had to measure a wide range of cell densities in a complex medium with a high amount of other non-cellular particles. With the exception of the large and fast changes in the number of cells, the maintenance of the broth sucrose content closely simulated the continuous mode of fermentation employed by producing plants (Basso et al., 2011).

The experiments were conducted in unbaffled glass vessels (250 mL working volume) equipped with a magnetic stirrer.

\section{Image acquisition}

This study used a custom-built high-resolution in situ microscope developed at the Mannheim University of Applied Sciences, Mannheim, Germany (Wiedemann et al., 2011). A schematic of the setup is shown in Figure 1.

Short illumination flashes are generated by an external luminescence diode and guided to the sampling zone by a U-shaped optical fiber, which separates the suspension from the objective. Due to the flash illumination, the cells moving by the window are imaged without blurring, despite their considerable speed $(0.1$ to $0.5 \mathrm{~m} / \mathrm{s})$. For critical reviews on in situ microscopy, please refer to, e.g., Höpfner et al. (2010) and Belini et al. (2013).

Unlike other in situ sampling techniques [i.e., mechanical sampling and decelerated flow through an observation zone; see Belini et al. (2013) for detailed information], the optical sampling ISM used here is a system that lets the suspension flow freely through the observation zone.

The technical data regarding the ISM are summarized as follows: objective lens $(\times 40, \mathrm{NA}=0.75$, object field $0.16 \times 0.22 \mathrm{~mm}^{2}$, water immersion); camera (A102f, Basler, Ahrensburg, Germany, 1,392 × 1,040 pixels, $6.6 \times$ $8.8 \mathrm{~mm}^{2}$, pixel size $6.45 \times 6.45 \mu \mathrm{m}^{2}$, bitmap, 8 bits); optical resolution approximately $0.5 \mu \mathrm{m}$; glass fiber diameter 300 $\mu \mathrm{m}$; luminescence diode (DieMOUNT, Wernigerode, Germany) peak-wavelength at $650 \mathrm{~nm}$; pulse width $4 \mu \mathrm{s}$.

\section{Cell detection algorithm}

Conventional image processing techniques were applied to the image data acquired by the ISM. The algorithm was developed using the WiT (DALSA, Waterloo, Ontario, Canada) and MATLAB (MathWorks, Ismaning, Germany) software. Figure 2 shows a flow diagram of the image evaluation algorithm. Further information on these steps can be found in Wiedemann et al. (2011).

Most cells of S. cerevisiae SA-1 have an approximately circular shape. Therefore, the Circular Hough Transformation (CHT) (Gonzalez and Woods, 2008) was used for cell detection. This technique also performs satisfactory on shapes that are not perfectly circular. In this study, the CHT was designed to deal with cells of varying 
morphologies, including perfectly circular to ellipticalshaped cells, and ranging from very small to large-sized ones. However, objects originally contained in the cell-free molasses, whose shapes and sizes could resemble those of yeast cells, will also be extracted by the CHT.

It was observed in the experiments that the yeast sizes were typically in a narrower range of values compared with the molasses components. This was used as one of the criteria for classification. In logical conjunction with this criterion, a narrow interval of circularity, measured as Roundness (Figure 2), was used. An interval of inhomogeneity within the portraits (Figure 2) was used as a third criterion in logical conjunction with the two other criteria.

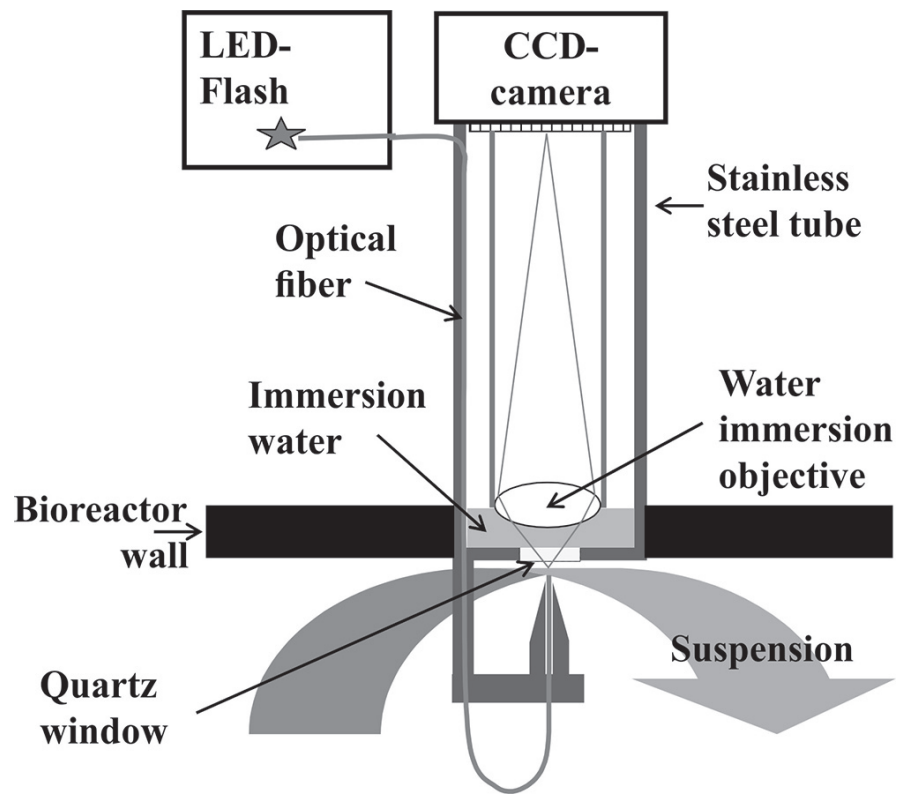

Figure 1. Set-up of the in situ microscope by Wiedemann et al. (2011).

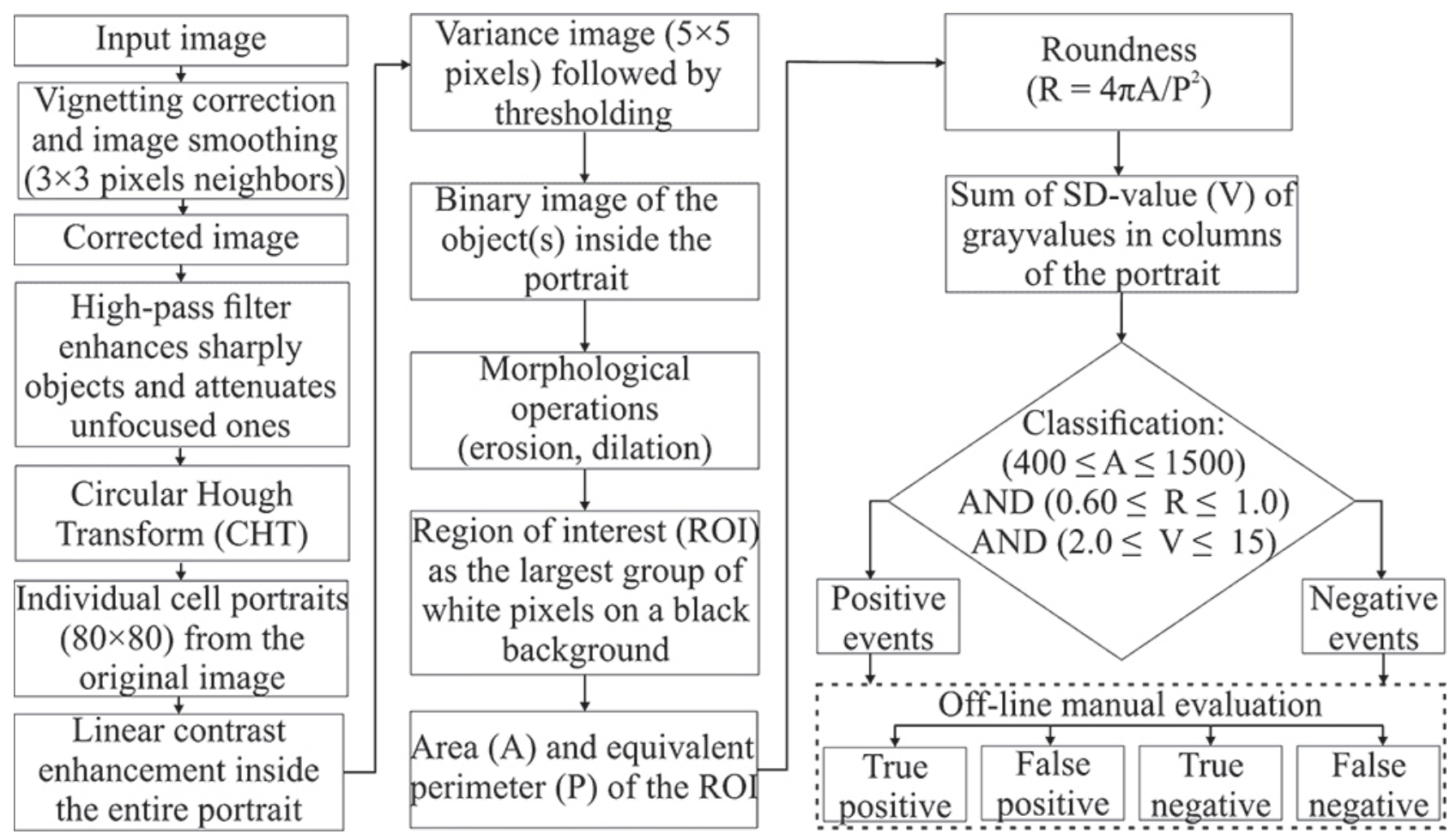

Figure 2. Flow diagram for the segmentation and classification of yeast cells in molasses. The threshold values used as criteria for the classification of the yeast cells were adjusted experimentally using a set of representative portraits (approximately 2000). 
The area of an object was characterized by the amount of white pixels after its segmentation. The shape of the region of interest (ROI) was characterized by Roundness $=4 \pi \times($ Area $) /(\text { Equivalent Perimeter })^{2}$. The inhomogeneity (granularity) of a cell was characterized by the sum of standard deviation (SD) values of grey values in columns of its portrait. The final block enclosed with a dashed line indicates the visual evaluation step of the automatic classification data. 'True positive'(TP) stands for correctly classified yeast cells, 'false positive'(FP) stands for other objects incorrectly classified as yeast cells, 'true negative'(TN) stands for objects correctly reported as noncellular, and 'false negative'(FN) stands for yeast cells incorrectly detected as other objects.

To evaluate the classification performance of the algorithm, the following criteria were used:

Sensitivity (proportion of real yeast cells that were recognized correctly):

$$
S E=\frac{T P}{T P+F N}
$$

Positive predictive value (proportion of positive objects that were actually yeast cells):

$$
P P V=\frac{T P}{T P+F P}
$$

Accuracy of the classification:

$$
A C C=\frac{T P+T N}{T P+F N+T N+F P}
$$

\section{RESULTS AND DISCUSSION}

\section{Yeast cell concentration}

Figure 3 shows representative images taken by the ISM in agitated solutions of cell-free industrial sugarcane molasses.

Figure 4 shows the characteristic appearance of suspended $S$. cerevisiae cells in industrial sugarcane molasses.

On average, 45 in-focus cells per image were observed at the highest cell concentration of $3.3 \times 10^{8}$ cells $/ \mathrm{mL}$. Altogether, approximately 6,600 individual cells were analyzed at this concentration. At the lowest concentration $\left(3.0 \times 10^{6} \quad\right.$ cells $\left./ \mathrm{mL}\right)$, approximately 2,500 cells were analyzed.

Each dilution cycle was documented with 120 ISM images, and analysis of the data for the six dilutions resulted in the relationship between ISM signal and manual counting shown in Figure 5.
The data points closest to each other corresponding to $9.5 \times 10^{6}$ and $8.6 \times 10^{6}$ cells $/ \mathrm{mL}$ resulted from the last dilution steps (see Methods). The deviation of the lowest data point from the linear fit originates from a significant number of false positive classifications of molasses-particles.

At higher concentrations, saturation is evidenced. It was also noticed that at the two highest cell densities, ISMimages exhibited less contrast. Images with lower contrast lead to less detection probability for cells and, consequently, to a saturation of the ISM counting rate, which is used to measure cell density (Figure 5). This effect has also been observed in a previous work in which cell density was measured using an ISM (Camisard et al., 2002). High cell densities also lead to a lower overall brightness of the images, i.e., to a turbidity effect apparent from the ISM image. In the case of prokaryotic fermentations, it has been shown that the turbidity effect in an ISM image can be used as a complementary method to estimate high cell densities, which tend to saturate the counting signal (Claus et al., 2013).

\section{Morphology of yeast cells}

Figure 6 shows ISM portraits of yeast cells suspended in molasses $\left(7^{\circ} \mathrm{Bx}\right)$. The portraits $(80 \times 80$ pixels $)$ were extracted from the original images after cell localization by the CHT.

Figure 6 shows that the ISM portraits of cells revealed morphological differences between rehydrated and propagated (after rehydration, see Methods) yeast cells. It can be seen that the rehydrated yeasts are more regular in shape (circular), more homogeneous with respect to intracellular structures and significantly smaller than the propagated cells. The latter are larger and, besides, show stronger intracellular heterogeneity and vacuolar structures, which might be a response to the rich nutritional medium (Zalewski and Buchholz, 1996).

Besides single cells and their internal structure, the ISM also captured the diversity of possible cell configurations (Figure 7) and that of other micro-objects originating from the molasses medium (Figure 8).

\section{Performance evaluation}

The classified portraits of cells and other objects were each visually assessed as true positive (TP), false positive (FP), true negative (TN) or false negative (FN). A representative set of these objects, together with the corresponding image processing, is shown in Figure 9.

Statistical data on the three evaluated features (size, roundness and inhomogeneity (granularity); see flow diagram in Fig. 2) for yeast cells and other micro-objects from all dilution-levels are summarized in Table 1.

The amount of data analyzed in this study (from approximately 10000 cells) is comparable to that in other recent studies (e.g., Bittner et al., 1998, and Wei et al., 2007). 

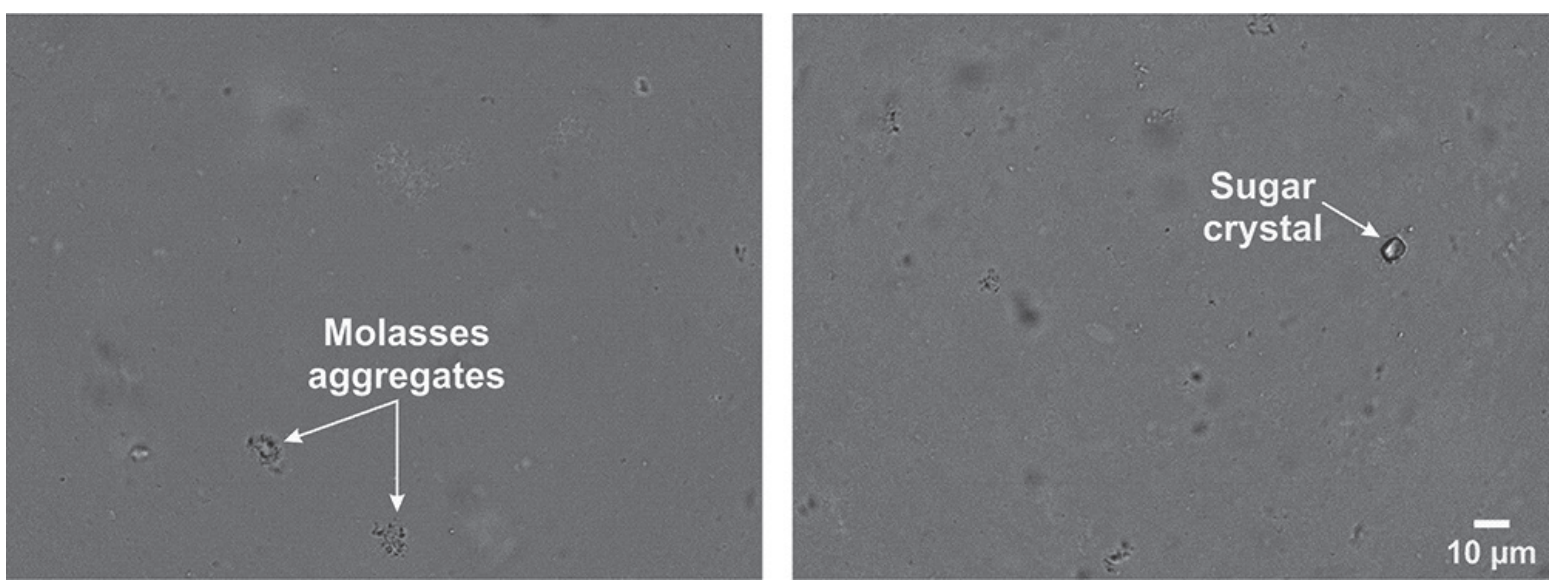

Figure 3. ISM images of cell-free molasses at different solid soluble concentrations: A: $7^{\circ} \mathrm{Bx}$. B: $14^{\circ} \mathrm{Bx}$. The different image brightness levels correspond to the different Brix values. For visualization purposes, contrast was enhanced.

As a preliminary measure of a cell's inhomogeneity, the sum of standard deviation values of grey values in columns of its portrait was used. However, this simple feature value suffers from the dependence on the size of the object. Nevertheless it was useful for discriminating cells from other objects with similar size and roundness in some suspensions (Table 1).

Table 2 shows the overall performance of the algorithm for each cell concentration. Since cells located between the illumination fiber and the focal plane can act as microlenses, leading to bright spots with smooth edges, while the ones located between the quartz window and the focal plane are dark, blurred spots (Bittner et al., 1998; Guez et $a l .$, 2004), they were accounted for as being TP. Budding cells and cell agglomerations were counted as a single cell (TP), provided they contained at least one in-focus cell (Figure 7). Moreover, large groups of lumped objects were automatically discarded by the algorithm, provided they were touching the portrait border.

Based on these data, the average values of the performance parameters were calculated as $S E=0.80$ and $P P V=0.92$.

At the lowest cell density, the positive predictive value was minimal: $P P V=56 \%$. The reason for this is that, at this low concentration, the amount of falsely positive molasses particles becomes comparable to the true positive counts.

The lower image contrast at high cell densities also affected the performance of the classification algorithm, resulting in an increased number of false negatives (Table 2). However, the straightforward classification approach used here still has a large potential for applying more refined techniques, e.g., using the overall image contrast and brightness as additional parameters allowing machine learning techniques to adapt the cell classification to the conditions of a high cell density.

Table 3 shows the accuracy values obtained at all dilution-levels. On the average, an accuracy of $A C C=0.80$ has been obtained.The processing time of less than $20 \mathrm{~s}$ per

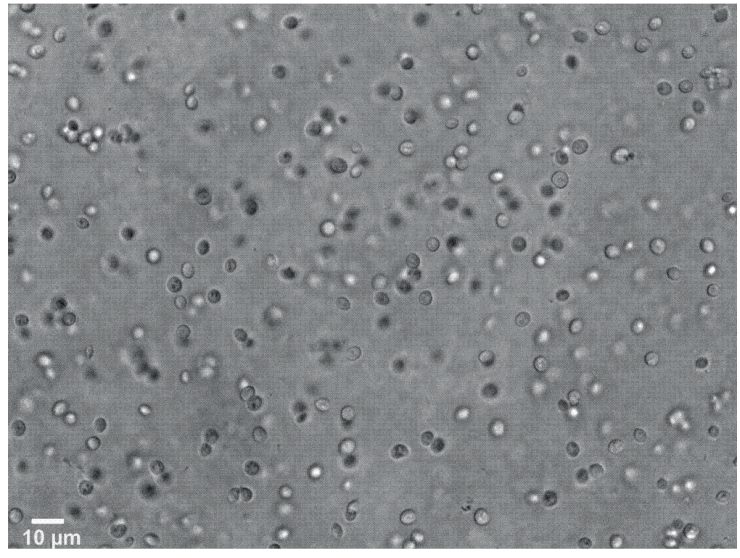

Figure 4. ISM image of a suspension of $S$. cerevisiae SA-1 in diluted molasses $\left(7^{\circ} \mathrm{Bx}\right)$. The cell density $\left(3.3 \times 10^{8}\right.$ cells $\left./ \mathrm{mL}\right)$ was determined by manual counting (Neubauer).

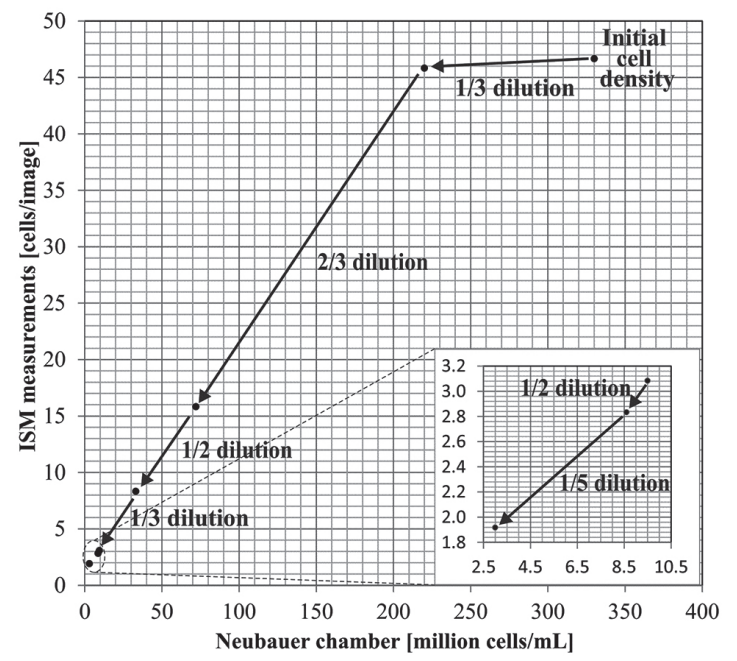

Figure 5. Counts of in-focus cells per ISM-image as a function of the manual cell count (four replicates). The solid dots represent the experimental measurements. The line represents a linear fit between the data points up to approximately $2 \times 10^{8}$ cells $/ \mathrm{mL}$. 

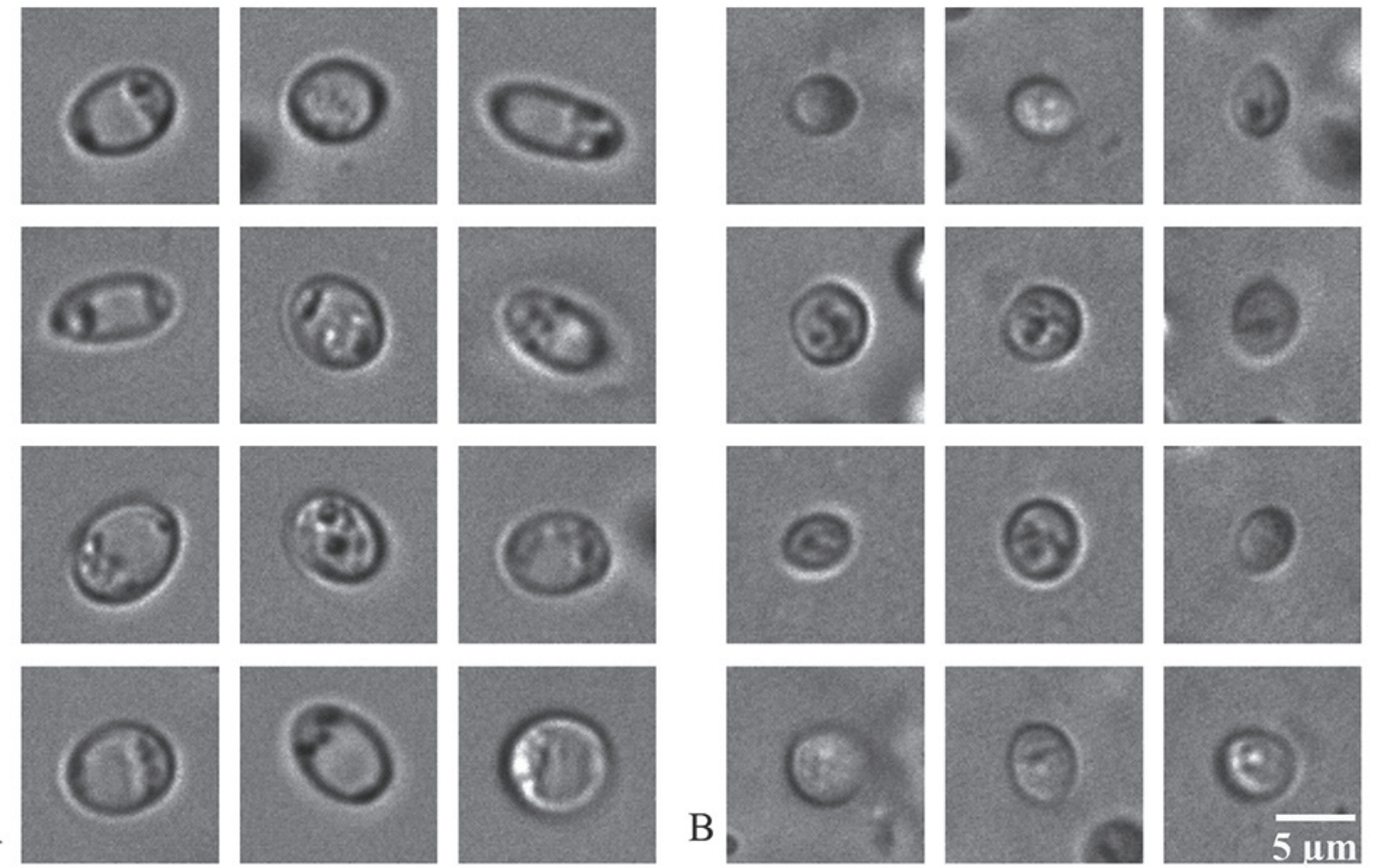

Figure 6. Yeast cell images captured by the ISM. A: yeast cells harvested during the growth phase. B: yeast cells harvested during the rehydration phase (see Methods).

A

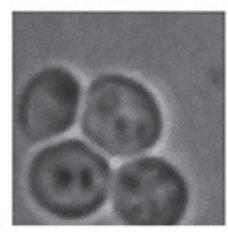

C

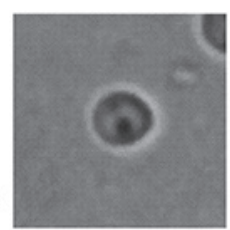

E

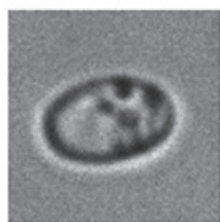

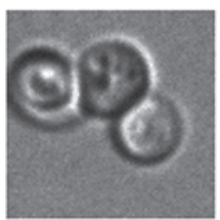
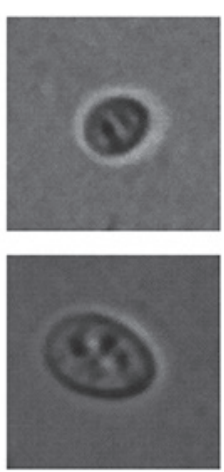
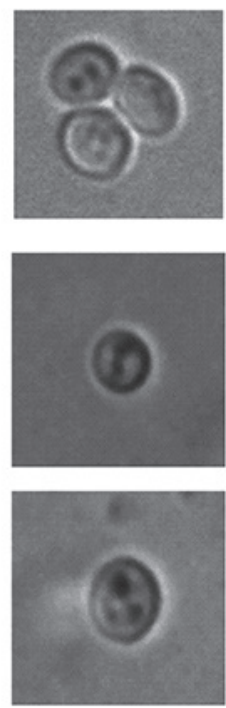

$\mathrm{B}$
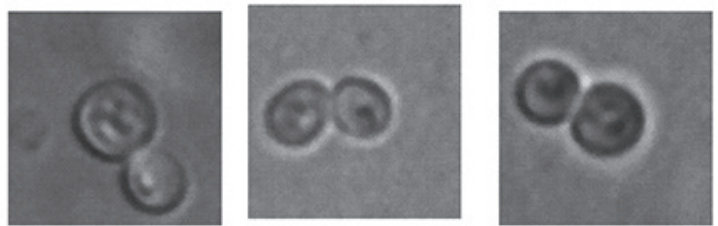

$\mathrm{D}$
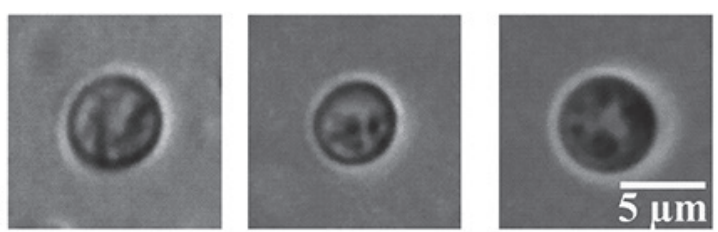

F
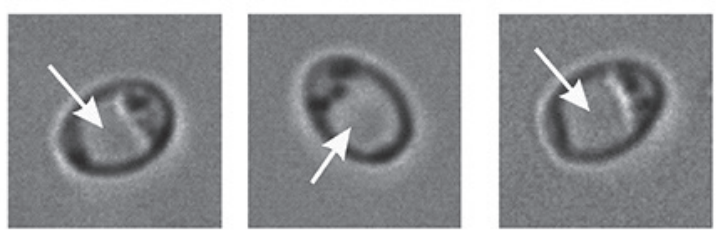

Figure 7. Overview of ISM portraits of yeast cells from the broth. A: clusters of cells. B: budding cells. C: cells smaller than average. D: cells larger than average. E: elliptical cells. F: cells with a visible vacuole. The arrow indicates a structure, which is probably a vacuole (compartment for nutrients and enzymes).

120 images (on an Intel PC, Quad-CPU, 2.66 GHz, 4.0 GB

data suitable for process automation in yeast fermentation.

RAM) was sufficiently short to be able to provide real-time 

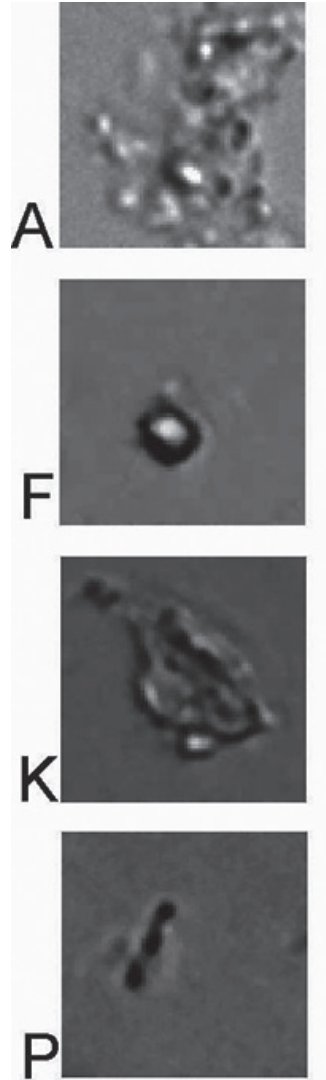
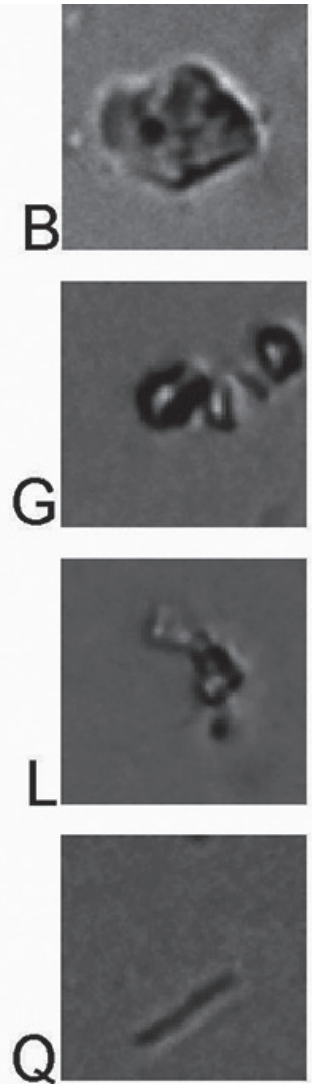
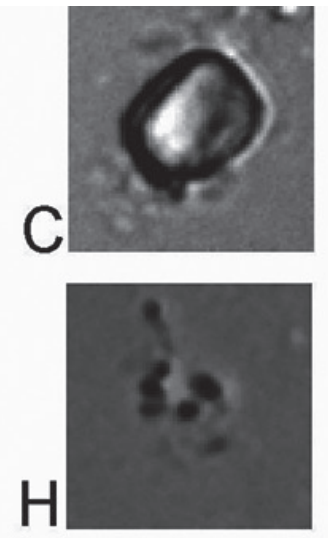

D
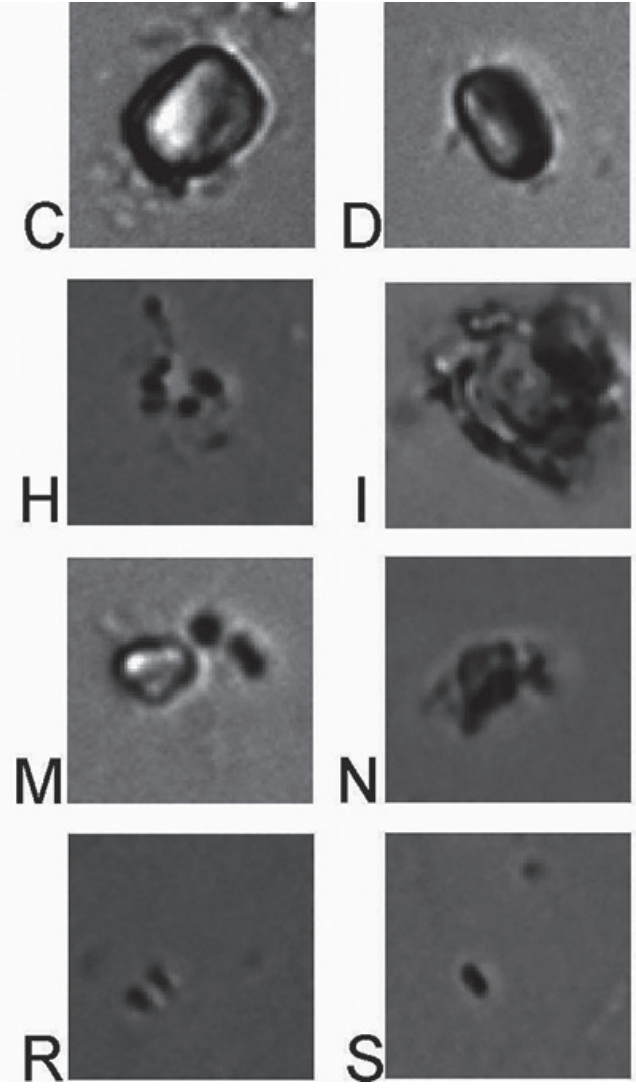
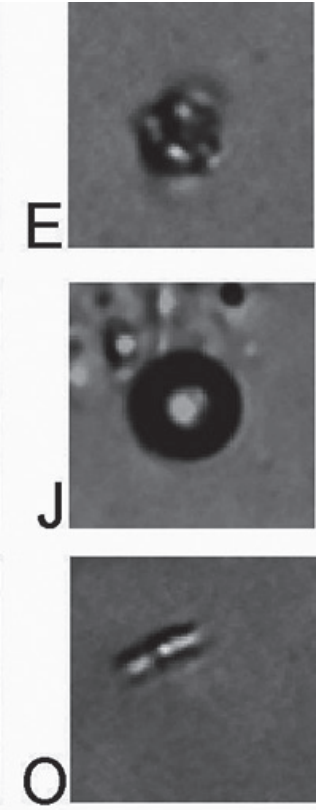

Figure 8. Collection of different molasses components from ISM images. A, H: molasses aggregates. C, D, F, M: sugar crystals. J: gas bubble. The objects in the other images could not be identified. They are probably due to sugar cane fiber fragmentation.

Table 1. Descriptive statistic for yeast cells and non-cellular micro-objects for each feature assessed over all dilutions. The data consist of the mean-value and the standard deviation computed on the sets of true positive objects (yeast cells) and true negative (non-cellular) objects.

\begin{tabular}{ccccccc}
\hline \multirow{2}{*}{ Suspension } & \multicolumn{2}{c}{ True positive objects (yeast cells) } & \multicolumn{2}{c}{ True negative objects (non-cellular) } \\
\cline { 2 - 7 } & $\begin{array}{c}\text { Size } \\
\text { [pixels }^{2} \text { ] }\end{array}$ & $\begin{array}{c}\text { Roundness } \\
{[\text { ] }}\end{array}$ & $\begin{array}{c}\text { Granularity } \\
\text { [graylevel] }\end{array}$ & $\begin{array}{c}\text { Size } \\
\text { [pixels }{ }^{2} \text { ] }\end{array}$ & $\begin{array}{c}\text { Roundness } \\
{[\text { ] }}\end{array}$ & $\begin{array}{c}\text { Granularity } \\
\text { [graylevel] }\end{array}$ \\
\hline 1 & $541.50 \pm 227.21$ & $0.74 \pm 0.17$ & $7.86 \pm 2.37$ & $275.83 \pm 218.75$ & $0.60 \pm 0.35$ & $4.98 \pm 2.71$ \\
2 & $582.20 \pm 212.99$ & $0.78 \pm 0.13$ & $8.13 \pm 2.10$ & $240.42 \pm 132.43$ & $0.61 \pm 0.17$ & $4.47 \pm 1.83$ \\
3 & $579.85 \pm 205.19$ & $0.80 \pm 0.12$ & $8.19 \pm 2.10$ & $161.36 \pm 135.34$ & $0.73 \pm 0.16$ & $3.51 \pm 2.26$ \\
4 & $588.75 \pm 212.21$ & $0.80 \pm 0.11$ & $8.04 \pm 1.93$ & $281.35 \pm 228.02$ & $0.70 \pm 0.18$ & $5.04 \pm 3.29$ \\
5 & $594.16 \pm 238.34$ & $0.79 \pm 0.12$ & $7.91 \pm 2.13$ & $197.77 \pm 124.77$ & $0.68 \pm 0.17$ & $3.83 \pm 1.97$ \\
6 & $564.84 \pm 232.97$ & $0.78 \pm 0.13$ & $7.63 \pm 2.14$ & $161.50 \pm 108.83$ & $0.70 \pm 0.17$ & $3.68 \pm 1.98$ \\
7 & $546.27 \pm 233.13$ & $0.79 \pm 0.12$ & $7.59 \pm 2.38$ & $127.57 \pm 88.15$ & $0.65 \pm 0.25$ & $2.78 \pm 1.62$ \\
\hline
\end{tabular}

Table 2. Performance of the cell classification algorithm at different yeast cell concentrations.

\begin{tabular}{|c|c|c|c|c|c|c|c|}
\hline Parameter & $\begin{array}{c}3.3 \times 10^{8} \text { cells } / \\
\mathrm{mL}\end{array}$ & $\begin{array}{c}2.2 \times 10^{8} \text { cells } / \\
\mathrm{mL}\end{array}$ & $\begin{array}{c}7.2 \times 10^{7} \text { cells } / \\
\mathrm{mL}\end{array}$ & $\begin{array}{c}3.3 \times 10^{7} \text { cells } / \\
\mathrm{mL}\end{array}$ & $\begin{array}{c}9.5 \times 10^{6} \text { cells } / \\
\mathrm{mL}\end{array}$ & $\begin{array}{c}8.6 \times 10^{6} \text { cells } / \\
\mathrm{mL}\end{array}$ & $\begin{array}{c}3.0 \times 10^{6} \text { cells } / \\
\mathrm{mL}\end{array}$ \\
\hline $\mathrm{TP}$ & 4693 & 2514 & 1282 & 788 & 330 & 304 & 261 \\
\hline FP & 2 & 3 & 7 & 10 & 24 & 9 & 201 \\
\hline $\mathrm{TN}$ & 6 & 7 & 11 & 14 & 63 & 28 & 621 \\
\hline $\mathrm{FN}$ & 1219 & 455 & 205 & 187 & 73 & 98 & 101 \\
\hline SE & 0.79 & 0.85 & 0.86 & 0.81 & 0.82 & 0.76 & 0.72 \\
\hline PPV & 0.99 & 0.99 & 0.99 & 0.99 & 0.93 & 0.97 & 0.56 \\
\hline
\end{tabular}



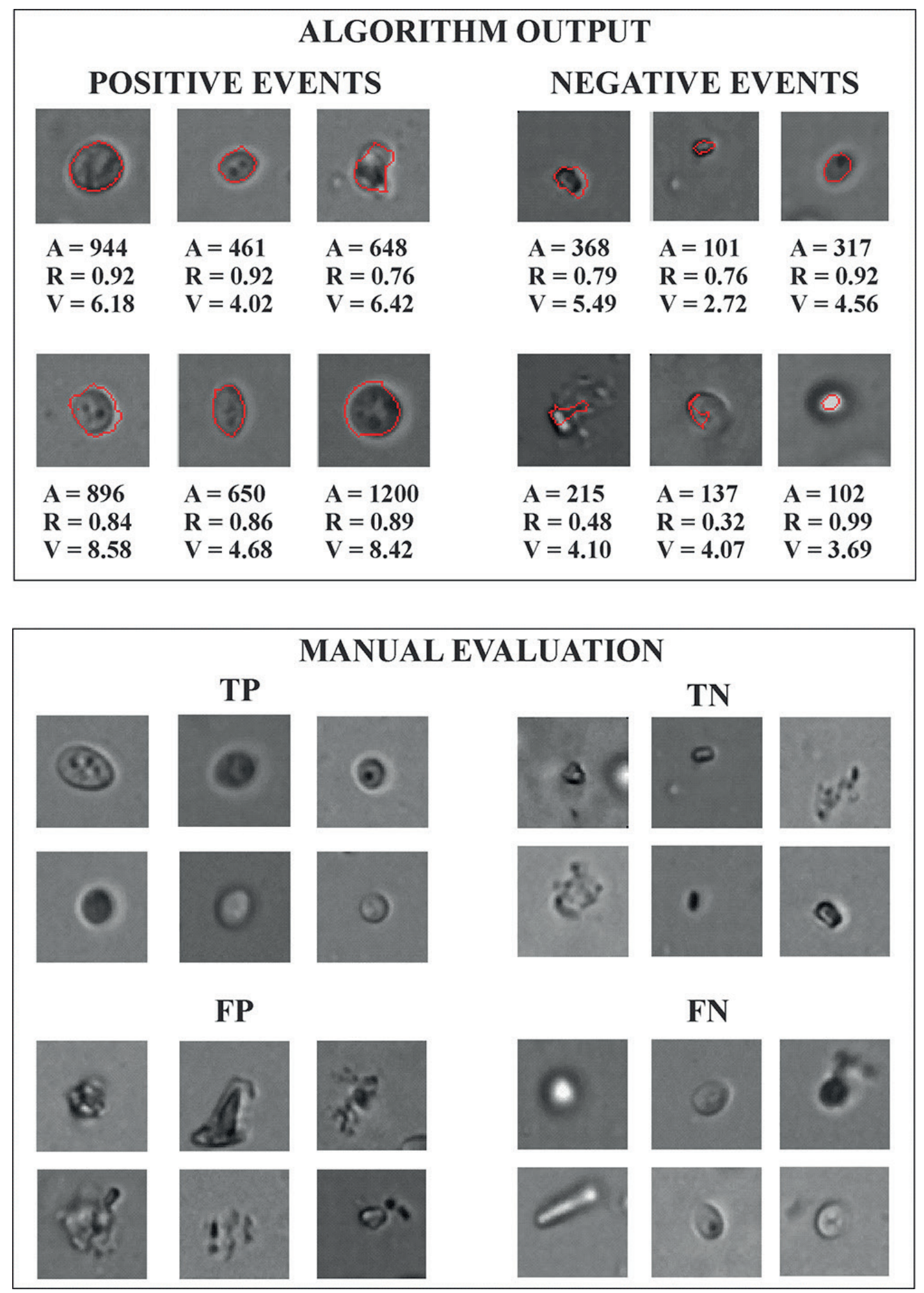

Figure 9. Representative examples of the objects automatically classified by the algorithm and evaluated by manual analysis.

Table 3. Accuracy for each set of image data.

\begin{tabular}{cccccccc}
\hline Concentration & $\begin{array}{c}3.3 \times 10^{8} \text { cells/ } \\
\mathrm{mL}\end{array}$ & $\begin{array}{c}2.2 \times 10^{8} \text { cells/ } \\
\mathrm{mL}\end{array}$ & $\begin{array}{c}7.2 \times 10^{7} \text { cells/ } \\
\mathrm{mL}\end{array}$ & $\begin{array}{c}3.3 \times 10^{7} \text { cells/ } \\
\mathrm{mL}\end{array}$ & $\begin{array}{c}9.5 \times 10^{6} \text { cells/ } \\
\mathrm{mL}\end{array}$ & $\begin{array}{c}8.6 \times 10^{6} \text { cells/ } \\
\mathrm{mL}\end{array}$ & $\begin{array}{c}3.0 \times 10^{6} \text { cells/ } \\
\mathrm{mL}\end{array}$ \\
\hline $\mathrm{ACC}$ & 0.79 & 0.84 & 0.86 & 0.80 & 0.80 & 0.75 & 0.74 \\
\hline
\end{tabular}




\section{CONCLUSIONS}

By determining yeast densities in an industrial molasses medium and in a range typical for industrial fermenters, this study demonstrated the potential of in situ microscopy as a tool for automated real-time monitoring of yeast cells in cane molasses.

Based on the high resolution of the cell portraits provided by the ISM, a straightforward classification algorithm using low-level image evaluation algorithms (Gonzalez and Woods, 2008) could differentiate between cells and other microscopically detected objects such as small sugar crystals, gas bubbles and other, non identified objects in the molasses medium. The quality of the ISM portraits (resolution and contrast) was fully comparable to that provided by laboratory microscopy after culture sampling. This performance enabled concentration measurements correlating linearly with reference measurements, up to a saturation level at high cell densities of approximately $2 \times 10^{8}$ per $\mathrm{mL}$. This finding is in agreement with previous work carried out by other authors (Suhr et al., 1995). Moreover, the large amount of image data greatly exceeds that obtained by conventional manual off-line techniques, leading to less statistical uncertainty in the cell density values measured.

In addition, it was demonstrated that the ISM resolved different morphologies in an industrially used yeast strain, thereby providing a basis for future studies of morphological features related to reagent-free cell viability classification (Wei et al., 2007; Tibayrenc et al., 2011). Morphological features have also been previously successfully exploited to assess the viability of animal cells (Wiedemann et al., 2011).

The monitoring of cell morphology as exhibited by the ISM utilized here is also a promising technique for an early warning system with respect to wild yeasts, which are detrimental to the fermentation process in many ways (de Souza Liberal et al., 2005; Reis et al., 2013). For example, morphological features such as pseudohyphae, which cannot be detected by optical density or $\mathrm{CO}_{2}$ measurements, make wild $S$. cerevisiae distinguishable from industrial strains.

In summary, it was shown that high-resolution noninvasive in situ microscopy offers the image quality needed for process monitoring and control in industrial sugarcane fermentation.

\section{ACKNOWLEDGMENTS}

This study was supported by grant 2012/01126-5 of the São Paulo Research Foundation (FAPESP), São Paulo, Brazil.

\section{REFERENCES}

Amorim, H.V., Lopes, M.L., Oliveira, J.V.C., Buckeridge, M.S., Goldman, G.H., Scientific challenges of bioethanol production in Brazil. Appl. Bioch. Biotech., 91, 1267-1275 (2011).

Basso, L.C., Basso, T.O., Rocha, S.N., Ethanol production in Brazil: the industrial process and its impacts on yeast fermentation. In: Biofuel Production-Recent Developments and Prospects. ISBN 978-953-307-478-8, September, 15, 85100 (2011).

Basso, L.C., Amorim, H.V., Oliveira, A.J., Lopes, M.L., Yeast selection for fuel ethanol production in Brazil. FEMS Yeast Res., 8, 1155-1163 (2008).

Belini, V.L., Wiedemann, P., Suhr, H., In situ microscopy: a perspective for industrial bioethanol production monitoring. Journal of Microbiol. Methods, 93, 224-232 (2013)

Bittner, C., Wehnert, G., Scheper, T., In situ microscopy for online determination of biomass. Biotech. Bioengineering, 60, 24-35(1998).

Brückerhoff, T., Frerichs, J.G., Joeris, K., Konstantinov, K., Scheper, T., In: Godia F, Fussenegger M (eds) Proceedings of the 18th ESACT Meeting. Springer, Spain (2005).

Carvalho-Netto, O.V., Carazzolle, M.F., Mofatto, L.S., Teixeira, P.J., Noronha, M.F., Calderón, L.A., Mieczkowski, P.A., Argueso, J.L., Pereira, G.A., Saccharomyces cerevisiae transcriptional reprograming due to bacterial contamination during industrial scale bioethanol production. Microb. Cell. Fact., 14(1), 13 (2015).

Ceccato-Antonini, S.R., Biotechnological implications of filamentation in Saccharomyces cerevisiae. Biotechnol. Lett., 30, 1151-61 (2008).

Camisard, V., Brienne, J.P., Cassar, J.Ph., Hammann, J., Suhr, H., Inline Characterization of Cell-Concentration and CellVolume in Agitated Bioreactors using In situ Microscopy: Application to Volume Variation induced by Osmotic Stress. Biotechnol. Bioeng., 78, 73-80(2002).

Claus, G., Mürle, R., Bhandiwad, A., Suhr, H., Application of in situ microscopy for the on-line monitoring of bacterial fermentation processes. http://events.dechema.de/events media/Messen+und+Regeln.pdf. Accessed March 10, 2016 (2013).

Costello, P.J. and Monk, P.R., Image analysis method for the rapid counting of Saccharomyces cerevisiae cells. Appl. Environ. Microbiol., 49, 863-866 (1985).

de Souza Liberal, A.T., Da Silva Filho, E.A., De Morais, J.O.F., Simões, D.A. and de Morais, M.A., Contaminant yeast detection in industrial ethanol fermentation must by rDNAPCR. Letters in Applied Microbiology, 40, 19-23 (2005).

Frerichs, J.G., Joeris, K., Scheper, T., Konstantinov, K., In situ Microscopy for on-line and in-line monitoring of cell populations in bioreactors. Animal Cell Technology: From Target to Market, ESACT Proceedings, 1, 452-454 (2001).

Gonzalez, R. and Woods, R., Digital Image Processing. 3rd Ed. Pearson Education (2008). 
Guez, J.S., Cassar, J.Ph., Wartelle, F., Dhulster, P., Suhr, H., Real time in situ microscopy for animal cell-concentration monitoring during high density culture in bioreactor. Journal of Biotechnology, 111, 335-343 (2004).

Höpfner, T., Bluma, A., Rudolph, G., Lindner, P., Scheper, T., A review on non-invasive optical-based image analysis systems for continuous bioprocess monitoring. Bioprocess. Biosyst. Eng., 33, 247-256 (2010).

Huls, P.G., Nanninga, N., Van Spronsen, E., A computer-aided measuring system for the characterization of yeast populations combining 2D-image analysis, electronic particle counter, and flow cytometry. Biotechnol. Bioeng., 39, 343-350 (1992).

Lynd, L.R., Weimer, P.J., van Zyl, W.H., Pretorius, I.S., Microbial cellulose utilization: fundamentals and biotechnology. Microbiol. Mol. Biol., 66, 506-77 (2002).

Oliva-Neto, P., Yokoya, F., Evaluation of bacterial contamination in fed-batch alcoholic fermentation process. W. J. Microbiol. Biotechnol., 10, 697-699 (1994).

Pons, M.N., Vivier, H., Remy, J.F., Dodds, J.A., Morphological characterization of yeast by image analysis. Biotechnol. Bioeng.,42, 1352-1359 (1993).

Reis, V.R., Bassi, A.P., da Silva, J.C., Ceccato-Antonini, S.R., Characteristics of Saccharomyces cerevisiae yeasts exhibiting rough colonies and pseudohyphal morphology with respect to alcoholic fermentation. Braz. J. Microbiol., 44, 1121-1131 (2013).

Suhr, H., Speil, P., Wehnert, G., Storhas, W., In-situ Mikroskopiesonde und Meßverfahren. Offenlegungsschrift. Deutsches Pattentamt. DE 4032002 A1 (1991).

Suhr, H.,Wehnert, G., Schneider, K., Bittner, C., Scholz, T., Geissler, P., Jähne, B., Scheper, T., In situ microscopy for on-line characterization of cell-populations in bioreactors, including cell-concentration measurements by depth from focus. Biotechnol. Bioeng., 47, 106-116 (1995).

Thomas, C.R. and Paul, G.C., Applications of image analysis in cell technology. Current Opinion in Biotechnology, 7, 35-45 (1996).

Tibayrenc, P., Preziosi-Belloy, L., Ghommidh, C., Single-cell analysis of S. cerevisiae growth recovery after a sublethal heat-stress applied during an alcoholic fermentation. Journal of Industrial Microbiology Biotechnology, 38, 687-696 (2011).

Tibayrenc, P., Preziosi-Belloy, L., Roger, J.M., Ghommidh, C., Assessing yeast viability from cell size measurements? Journal of Biotechnol., 149, 74-80 (2010).

Wei, N., Sommer, B. Cell Viability, Measurement. In: Encyclopedia of Industrial Biotechnology: Bioprocess. Bioseparation, Cell Technology. Wiley. 1-7 (2010).

Wei, N., You, J., Friehs, K., Flaschel, E., Nattkemper, T.W., An in-situ probe for on-line monitoring of cell density and viability on the basis of dark field microscopy in conjunction with image processing and supervised machine learning. Biotechnol. Bioeng., 97, 1489-1500 (2007).

Wiedemann, P., Guez, J.S., Wiegemann, H.B., Egner, F., Quintana, J.C., Asanza-Maldonado, D., Filipaki, M., Wilkesman, J., Schwiebert, C., Cassar, J.P., Dhulster, P., Suhr, H., In situ microscopic cytometry enables noninvasive viability assessment of animal cells by measuring entropy states. Biotechnol. Bioeng., 108, 2884-2893 (2011).

Zalewski, K., Buchholz, R., Morphological analysis of yeast cells using an automated image processing system. Journal of Biotechnology, 48, 43-49 (1996). 